\title{
Pengaruh model pembelajaran kooperatif tipe NHT dalam setting lesson study terhadap hasil belajar pendidikan jasmani
}

\author{
I Komang Ngurah Wiyasa \\ Pendidikan Guru Sekolah Dasar Fakultas IImu Pendidikan, Universitas Pendidikan Ganesha, \\ Jln. Udayana Singaraja \\ E-mail: komang.wiyasa@yahoo.com
}

\begin{abstract}
Abstrak
Penelitian ini bertujuan untuk mengetahui perbedaan yang signifikan hasil belajar Penjas antara mahasiswa PGSD FIP Undiksha semester IV UPP Denpasar tahun 2016/2017 yang dibelajarakan menggunakan model pembelajaran tipe NHT dalam setting lesson study dan mahasiswa yang dibelajarakan secara konvensional. Jenis penelitian ini adalah eksperimen semu dengan rancanagan nonequivalent control group design. Populasi penelitian adalah mahasiswa PGSD FIP Undiksha semester IV UPP Denpasar tahun2016/2017. Sampel kelas terteliti ditentukan dengan teknik random sampling. Dalam penelitian ini sampel terteliti adalah dua kelas, satu kelas eksperimen dan satu kelas kontrol. Penentuan sampel sebagai kelas eksperimen dan kelas kontrol dilakukan dengan cara diundi. Data penelitian berupa hasil belajar penjas diperoleh dengan metode tes yakni tes baku keterampilan atletik yang dilakukan diakhir kegiatan penelitian (post test). Selanjutnya data yang terkumpul dianalisis dengan menggunakan analisis uji-t. Berdasarkan hasil perhitungan dan analisis uji-t, diperoleh thitung sebesar 27,24. Harga tersebut kemudian dibandingkan dengan haraga $t_{\text {tabel }}$ dengan $\mathrm{dk}=45+45-2=88$ dan taraf signifikan $5 \%$ diperoleh harga $t_{\text {tabel }} 2,00$. Oleh karena $t_{\text {hitung }}>t_{\text {tabel }}$ $(27,24>2,00)$ maka $\mathrm{H}_{0}$ ditolak dan $\mathrm{H}_{\mathrm{a}}$ deterima. Hal ini dapat disimpulkan bahwa terdapat perbedaan yang signifikan antara hasil belajar pendidikan jasmani mahasiswa yang dibelajarkan dengan menggunakan model pembelajaran tipe NHT dalam setting lesson study dengan mahasiswa yang dibelajarkan secara konvensional.

Kata kunci : Model pembelajaran tipe NHT, setting lesson stydy, pendidikan jasmani.
\end{abstract}

\section{The influance of cooperative learning model type NHT in setting lesson on physical education learning}

\begin{abstract}
This study aims to determine significant differences between student learning outcomes Penjas PGSD FIP Undiksha fourth semester UPP Denpasar year 2016/2017 that learned using a whole by setting the famil-lesson study and students who dibelajarakan conventionally. The research is a quasi experiment with a scheme would nonequivalent control group design. The study population was a student of fourth semester PGSD FIP Undiksha UPP Denpasar year 2014/2015. Terteliti grade samples is determined by random sampling technique. In this study sample terteliti are two classes, one class experimental and one control class. Determination of the sample as an experimental class and grade control is done by a draw. The research data in the form of physical education learning outcomes obtained with a test method which is a standard test conducted at the end of playing skills, research activities (posttest). Furthermore, the data were analyzed using t-test analysis. Based on the calculation and $t$-test analysis, obtained $t_{\text {hitung }}$ 27.24. This price is then compared with haraga $t_{\text {tabel }}$ with $d f=45$ $+45-2=88$ and a significance level of $5 \%$ was obtained $t_{\text {tabel }}$ price of 2.00 . Therefore $t_{\text {hitung }}>$ $t_{\text {table }}(27.24>2.00) H_{0}$ rejected and $H_{a}$ deterima. This means there is a significant difference between the results of student learning that learned by using part-whole by setting lesson study with students that learned conventionally. Top results
\end{abstract}


Jurnal Pendidikan Jasmani Indonesia, 13 (2), 2017 - 73

I Komang Ngurah Wiyasa

Keywords: Cooperative learning model tipe NHT, Lesson study, Physical education learning outcomes.

\section{PENDAHULUAN}

Pendidikan merupakan faktor yang sangat penting bagi kehidupan suatau bangsa, karena pendidikan adalah salah satu aspek yang dapat mendorong meningkatnya sumber daya manusia. Mulyasa (2011:4) menyatakan bahwa pendidikan dapat memberikan kontribusi besar terhadap kemajuan suatu bangsa serta sebagai sebagai sarana dalam membangun kepribadian bangsa. Pendidikan yang berkualitas, sangat ditentukan oleh komponenkomponen pendidikan itu sendiri.

Berbagai upaya telah dilakukan oleh pemerintah untuk meningkatkan kualitas pendidkan di Indonesia, diantaranya dengan melakukan berbagai inovasi dalam penerapan model, metode, strategi, maupun media pembelajaran. Dengan adanya upaya tersebut menuntut guru demikian pun dosen untuk dapat memadukan antara tuntutan pendidikan dan perkembangan pendidikan yang terjadi demi meningkatkan kualitas pembelajaran di sekolah atau juga di kampus. Singkat kata pendidkan akan berhasil baik bila proses pembelajaran di kelas dapat berjalan dengan baik pula. Guru dan dosen sebagai ujung tombak pelaksana pembelajaran//perkuliahan memiliki peran yang sangat penting.

Pada dasarnya Pembelajran ataupun perkuliahan merupakan proses komunikasi yang bersufat timbal balik antara dosen dan mahasiswa, mahasiswa dengan mahasiswa untiuk mencapau tujuan perkuliahan yang telah ditetapkan secara efektif. Dalam hal ini mahasiswa diperlakukan sebagai subjek utama dalam proses perkuliahan dan dosen menempati posisi yang cukup sentral dan strategis untuk dapat menciptakan suasana perkuliahan yang kondusif, sehingga dapat mengarahkan mahasiswa untuk mencapai tujuan perkuliahan secara optimal.

Dengan adanya berbagai inovasi dalam penerapan model, metode, strategi pembelajaran dan berkembangnya teknologi pendidikan, kegiatan perkuliahan dapat dilaksanakan secara optimal sesuai dengan karakteristik mata kuliah. Hal ini dimaksudkan agar mahasiswa mudah menyerap dan mengaplikasikan materi perkuliahan yang diberikan. Salah satu materi perkuliahan yang diberikan pada mahasiswa jurusan Pendidkan Guru Sekolah Dasar (PGSD) adalah Pendidikan Jasmani (Penjas). Terdapat enam manfaat pendidikan jasmani bagi siswa baik ketika dilakukan di sekolah maupun saat dilakukan di rumah. keenam manfaat tersebut yakni: meningkatkan pertumbuhan dan perkembangan; meningkatkan kesehatan; meningkatkan kesegaran jasmani; meningkatkan ketangkasan/keterampilan; meningkatkan pengetahuan dan kecerdasan; dan menanamkan kehidupan kreatif rekreatif, dan sosial

Sebagai sebuah mata kuliah atau mata pelajaran, pendidkan jasmani terbagi dalam beberapa cabang olahraga. Salah satu cabang olahraga yang cukup banyak berkontribusi terhadap pertumbuhan dan perkembangan kompetensi siswa dalam cabang olahraga atletik Pada umumnya manusia memiliki kecenderungan selalu ingin bergerak sambil bersenang senang untuk menyalurkan segala potensi yang ada pada dirinya. Bentuk-bentuk kegiatan tersebut disalurkan melalui aktivitas gerak. Bagi seorang anak gerak merupakan suatu kebutuhan yang tak ubahnya seperti kebutuhan dasar lainnya. Ini terkait dengan naluri bergerak yang merupakan kodrat seorang anak. Bila kita sependapat bahwa sebagian besar kehidupan anak dihabiskan untuk bergerak, permasalahannya sekarang adalah bagaimana menyalurkan potensi tersebut agar bermanfaat bagi pertumbuhan dan perkembangannya. Usia siswa kelas sekolah dasar adalah masa penting untuk pertumbuhan baik fisik, mental, emosional, intelektual, sosial. Oleh karena itu sangat diharapkan bahwa bergerak merupakan wahana pembelajaran pendidkan jasmani yang menyenangkan. Ibaratnya belajar melalui gerak, atau melaui bergerak dapat tercipta suatu kegiatan belajar yang menyenangkan. Akhirnya pendidkan jasmani sebagai pendidkan yang menyeluruh pun akan tercapai (Toho Cholik dan Rusli Lutan, 1997). 
Dalam bukunya berjudul Pembelajaranolahraga atletik, Syamsir Aziz (2004) mengemukakan ada 3 jenis kegiatan yaitu : (1), official games (2) Lead games, dan (3) Loe organization games.

Official games adalah suatu jenis kegiatan yang telah memiliki organisasi resmi dan diakui oleh tingkat nasional maupun internasional. Peraturan yang ada dalam olahraga atletik ini sudah baku dan tidak bisa diubah. Dalam pembelajaran pendidikan jasmani di sekolah dasar atletik jenis ini belum akan diberikan sebelum siswa memiliki kematangan sampai pada penguasaan keterampilan pesivikasi dan spesialisasi. Berbeda dengan official games, lead games merupakan satu jenis kegiatan yang pada umumnya diberikan dalam pembelajaran pendidikan jasmani di sekolah dasar, dengan syarat siswa sudah mengusai berbagai keterampilan gerak dasar. Hal tersebut dikarenakan permainan ini merupakan jenis kegiatan dimodifikasi dan mengarah pada olahraga resmi yang akan dipelajari. Perbedaanya hanyalah pada lead games peraturan dan aturan aturan lainya dapat dimodifikasi atau diubah.

Sedangkan low organisation games adalah kegiatan yang mempunyai peraturan yang tidak mengikat. Pada umumnya lo organistion games ini disebut juga aktivitas gerak anak. Peraturan, alat, lapangan, serta pemain yang melakukan tidak ditentukan oleh suatu peraturan resmi. Kgiatan ini dapat diciptakan oleh siapa saja yang akan memakainya, baik oleh siswa maupun guru yang akan memberikan pembelajaran pada siswa. Meski tidak memiliki peraturan yang mengaikat, jenis kegiatan ini tetap memiliki rambu-rambu peraturan. Guru yang bijaksana akan menciptakan berbagai aktivitas gerak yang sangat berguna dan menunjang tujuan pembelajaran pendidikan jasmani. Jenis kegiatan yang diciptakan guru diusahakan menarik, mengembirakan, sesuai dengan taraf perkembangan dan kemampuan siswa. Aktivitas gerak dapat diperguanakan sebagai alat dalam membantu proses pembelajaran pendidikan jasmani guna menunjang tercapainya tujuan. Olahraga atletik juga merupakan alat untuk mendidikan anak. Dengan demikian dalam menciptakan aktivitas perlu mempertimbangkan hal-hal yang berkaitan dengan berkembangnya domain kognitif, domain afektif, domain prikomotor, serta sosial emosionalnya.

\section{METODE}

Penelitian ini merupan penelitian kuantitatif dengan rancangan penelitian eksperimen semu (quasy experiment). Penelitian ini dilaksanakan pada mahasiswa PGSD FIP Undiksha semester IV UPP Denpasar tahun 2017 Populasi penelitian adalah mahasiswa PGSD FIP Undiksha semester IV UPP Denpasar tahun kuliah2016/2017. Adapun sampel kelas terteliti yakni kelas $\mathrm{J}$ berjumlah 47 mahasiswa sebagai kelas eksperimen dan kelas kontrol adalah kelas $\mathrm{K}$ berjumlah 53 mahasiswa diperoleh secara acak dengan teknik random sampling .kelas eksperiment adalah kelas $\mathrm{J}$ yang diberikan perlakuan berupa pembelajaran penjas dengan model kooperatif tipe NHT dalam setting lesson study. Sedangkan kelas kontrol adalah kelas $\mathrm{K}$ yang dijadikan sebagai pembanding tanpa diberikan perlakuan. Desain eksperimen yang digunakan adalah nonequivalent control group design. Data hasil belajar penjas dalam penelitian ini diambil dari skor posttest saja.

Dalam penelitian ini terdapat 2 jenis variabel yaitu, variabel bebas (independen) dan variabel terikat (dependen). Variabel bebas dalam penelitian ini adalah model kooperatif tipe NHT dalam setting lesson study dalam pembelajaran penjas dan pembelajaran penjas secara kovensional. Variabel terikat dalam penelitian ini adalah hasil belajar penjas mahasaiaswa PGSD Undiksha UPP Denpasar semester IV tahun kuliah2017. Metode pengumpulan data yang digunakan adalah metode tes. Instrument yang digunakan untuk mengukur hasil belajar penjas adalah tes keterampilan baku berupa intruksi-intruksi untuk melakukan gerakangerakan tehnik lompat jauh gaya jongkok sarana yang ditetapkan. Setiap item tes diberikan skor.

\section{HASIL DAN PEMBAHASAN}

Hasil penelitian berupa hasil kaji tindak pembelajaran penjas yang dilakukan pada kela $\mathrm{J}$ dan kelas $\mathrm{K}$ semester IV dengan masing-masing anggota kelas berjumlah 50 sebagai kelas terteliti. Terhadap kedua kelas terteliti diberikan tes keterampilan awal Tes yang diberikan 
pada kedua kelas terteliti adalah tes keterampilan olahraga lompat jauh gaya jongkok Hasil tes keterampilan awan kedua kelas terteliti berupa skor/nilai tersaji dalam tabel 1.

Tabel 1. Data Hasil Test Awal Keterampilan Lompat Jauh Gaya Jongkok pada Kelas Eksperimen dan Kelas Kontrol

\begin{tabular}{|c|c|c|c|c|}
\hline \multirow{2}{*}{ No. } & \multicolumn{2}{|c|}{ Kelas Kontrol } & \multicolumn{2}{|c|}{ Kelas Eksperimen } \\
\hline & Kode & Hasil & Kode & Hasil \\
\hline 1. & K1 & 4.78 & E1 & 5.56 \\
\hline 2. & K2 & 7.44 & E2 & 5.78 \\
\hline 3. & K3 & 7.00 & E3 & 6.44 \\
\hline 4. & K4 & 5.67 & E4 & 6.00 \\
\hline 5. & K5 & 6.89 & E5 & 6.67 \\
\hline 6. & K6 & 7.00 & E6 & 7.44 \\
\hline 7. & K7 & 7.56 & E7 & 5.89 \\
\hline 8. & K8 & 5.11 & E8 & 5.44 \\
\hline 9. & K9 & 5.44 & E9 & 6.89 \\
\hline 10. & K10 & 7.22 & E10 & 5.67 \\
\hline 11. & $\mathrm{~K} 11$ & 5.56 & E11 & 4.89 \\
\hline 12. & $\mathrm{~K} 12$ & 6.67 & E12 & 5.67 \\
\hline 13. & K13 & 5.56 & E13 & 4.89 \\
\hline 14. & K14 & 6.33 & E14 & 5.89 \\
\hline 15. & K15 & 6.56 & E15 & 5.56 \\
\hline 16. & K16 & 5.89 & E16 & 5.22 \\
\hline 17. & K17 & 6.00 & E17 & 6.78 \\
\hline 18. & K18 & 6.22 & E18 & 6.00 \\
\hline 19. & K19 & 4.89 & E19 & 6.33 \\
\hline 20. & K20 & 5.33 & E20 & 7.56 \\
\hline 21. & K21 & 6.22 & E21 & 7.44 \\
\hline 22. & K22 & 7.78 & E22 & 7.00 \\
\hline 23. & $\mathrm{~K} 23$ & 6.33 & E23 & 6.78 \\
\hline 24. & K24 & 5.22 & E24 & 7.11 \\
\hline 25. & K25 & 5.89 & E25 & 6.56 \\
\hline 26. & K26 & 5.78 & E26 & 7.22 \\
\hline 27. & K27 & 6.00 & E27 & 6.89 \\
\hline 28. & K28 & 6.56 & E28 & 7.22 \\
\hline 29. & K29 & 7.00 & E29 & 6.44 \\
\hline 30. & K30 & 5.89 & E30 & 5.78 \\
\hline 31. & K31 & 6.78 & E31 & 5.56 \\
\hline 32. & K32 & 6.33 & E32 & 5.11 \\
\hline 33. & K33 & 6.00 & E33 & 5.56 \\
\hline 34. & K34 & 7.22 & E34 & 6.33 \\
\hline 35. & K35 & 6.78 & E35 & 6.56 \\
\hline 36. & K36 & 5.56 & E36 & 5.89 \\
\hline 37. & K37 & 7.00 & E37 & 7.00 \\
\hline 38. & K38 & 5.89 & E38 & 7.78 \\
\hline 39. & K39 & 4.67 & E39 & 6.78 \\
\hline 40 & K40 & 7.56 & E40 & 7.00 \\
\hline 41. & K41 & 7.11 & E41 & 7.56 \\
\hline 42. & K42 & 6.89 & E42 & 7.00 \\
\hline 43. & $\mathrm{~K} 43$ & 4.22 & E43 & 6.33 \\
\hline 44. & K44 & 7.78 & E44 & 6.22 \\
\hline 45. & K45 & 4.67 & E45 & 5.33 \\
\hline 46. & K46 & 6.44 & E46 & 6.78 \\
\hline 47. & K47 & 5.11 & E47 & 6.33 \\
\hline 48. & K48 & 4.67 & E48 & 6.22 \\
\hline 49. & K49 & 5.56 & E49 & 4.78 \\
\hline 50. & K50 & 6.33 & E50 & 6.00 \\
\hline
\end{tabular}

Hasil teks keterampilan awal 50 orang mahasiswa dari masing-masing kelompok selanjut.nya dilakukan uji kesetaraan/maching dan diperoleh hasil 45 orang yang nilainya 
setara/sama. Mahasiswa yang tidak mendapatkan pasangan dimortalitas. Namun demikian, kelima mahasiswa yang tidak mendapat pasangan tersebut tetap diikutkan dalam kegiatan penelitian ini dengan catatan nilai yang diperoleh pada tes akhir tidak diikutkan dalam analisis data. Setelah dilakukan kegiatan kaji tindak pembelajaran sesuai dengan rencana yakni pembelajaran keterampilan lompat jauh gaya jongkok dengan model kooperatif tipe NHT di kelas eksperimen dan pembelajaran secara konvensional pada kelas kontrol akhirnya dilakukan tes akhir kegiatan penelitian. Hasil test akhir kaji tindak pembelajaran lompat jauh gaya jongkok dapat dilihat pada tabel 2 .

Tabel 2. Data Hasil Tes Akhir Keterampilan Lompat Jauh Gaya Jongkok pada Kelas Eksperimen dan Kelas Kontol

\begin{tabular}{|c|c|c|c|c|}
\hline \multirow{2}{*}{ No. } & \multicolumn{2}{|c|}{ Kelas Kontrol } & \multicolumn{2}{|c|}{ Kelas Eksperimen } \\
\hline & Kode & Hasil & Kode & Hasil \\
\hline 1. & K1 & 5.89 & E1 & 7.22 \\
\hline 2. & K2 & 6.22 & E2 & 8.33 \\
\hline 3. & K3 & 6.33 & E3 & 8.44 \\
\hline 4. & K4 & 6.22 & E4 & 8.22 \\
\hline 5. & K5 & 5.89 & E5 & 8.67 \\
\hline 6. & K6 & 5.56 & E6 & 7.89 \\
\hline 7. & K7 & 5.22 & E7 & 8.00 \\
\hline 8. & K8 & 6.33 & E8 & 7.33 \\
\hline 9. & K9 & 6.56 & E9 & 7.44 \\
\hline 10. & K10 & 6.56 & E10 & 7.78 \\
\hline 11. & K11 & 6.11 & E11 & 8.33 \\
\hline 12. & K12 & 5.67 & E12 & 8.00 \\
\hline 13. & K13 & 5.67 & E13 & 7.89 \\
\hline 14. & K14 & 5.78 & E14 & 8.22 \\
\hline 15. & K15 & 5.56 & E15 & 7.22 \\
\hline 16. & K16 & 5.56 & E16 & 8.33 \\
\hline 17. & K17 & 5.67 & E17 & 7.78 \\
\hline 18. & K18 & 5.78 & E18 & 8.44 \\
\hline 19. & K19 & 5.44 & E19 & 8.44 \\
\hline 20. & K20 & 5.44 & E20 & 8.11 \\
\hline 21. & K21 & 6.56 & $\mathrm{E} 21$ & 8.84 \\
\hline 22. & K22 & 5.89 & E22 & 8.78 \\
\hline 23. & $\mathrm{~K} 23$ & 5.33 & E23 & 6.78 \\
\hline 24. & K24 & 5.78 & E24 & 7.67 \\
\hline 25. & K25 & 6.00 & E25 & 7.89 \\
\hline 26. & K26 & 5.89 & E26 & 8.67 \\
\hline 27. & K27 & 5.44 & E27 & 8.33 \\
\hline 28. & K28 & 5.78 & E28 & 8.78 \\
\hline 29. & K29 & 5.89 & E29 & 8.44 \\
\hline 30. & K30 & 5.89 & E30 & 8.00 \\
\hline 31. & K31 & 6.33 & E31 & 8.56 \\
\hline 32. & K32 & 6.44 & E32 & 8.44 \\
\hline 33. & K33 & 6.11 & E33 & 8.22 \\
\hline 34. & K34 & 5.56 & E34 & 7.89 \\
\hline 35. & K35 & 6.00 & E35 & 8.22 \\
\hline 36. & K36 & 5.78 & E36 & 7.67 \\
\hline 37. & K37 & 5.89 & E37 & 7.89 \\
\hline 38. & K38 & 5.67 & E38 & 7.56 \\
\hline 39. & K39 & 5.67 & E39 & 8.22 \\
\hline 40 & K40 & 6.67 & E40 & 7.78 \\
\hline 41. & K41 & 6.00 & E41 & 7.67 \\
\hline 42. & K42 & 6.11 & E42 & 8.22 \\
\hline 43. & K43 & 5.33 & E43 & 7.78 \\
\hline 44. & K44 & 5.56 & E44 & 8.00 \\
\hline 45. & K45 & 5.44 & E45 & 8.56 \\
\hline
\end{tabular}


Pada penghitungan homogenitas varian diperoleh hasil $F_{\text {hitung }}=1,19$ harga ini kemudian dibandingkan dengan dengan haraga $F_{\text {tabel }}$ dengan derajat pembebasan pembilang $=45-1=$ 44 dan derajat pembebasan penyebut $45-1=44$ dengan taraf signifikansi $5 \%$ sehingga diperoleh $F_{\text {tabel }}=1,66$. Karena haraga $F_{\text {hitung }}<F_{\text {tabel }}\left(1,19<1,66\right.$ maka $H_{\circ}$ dan $H_{a}$ ditolak). Ini berarti varian data bermain kasti antara kelompok eksperimen dan kelompok kentrol adalah sama atau homogen

Pada penghitungan normalitas nilai $X^{2}$ tabel pada taraf signifikansi $5 \%(\alpha=0,95)$ dan derajat kebebasan $(\mathrm{dk}=6-1=5)$ adalah 11,07 dan hasil analisis $X^{2}{ }_{\text {hitung }}=\sum_{1}^{6} \frac{(\mathrm{fo}-\mathrm{fe}) 2}{\mathrm{fe}}=1,08$ sehingga $\mathrm{X}^{2}$ hitung $<\mathrm{X}^{2}$ tabl maka data berdistribusi normal

Berdasarkan perhitungan uji normalitas ddata dan uji homogenitas varian diketahui bahwa data yang diperoleh berdistribusi normal dan memiliki varian yang homogen, maka untuk menguji hipotesis penelitian digunakan rumus uji-t polled varians.dari hasil perhitungan, diperoleh $t_{\text {hitung }}$ sebesar 27,24 . harga tersebut kemudian dibandingkan dengan harga $t_{\text {tabel }}$ dengan $\mathrm{dk}=45+45-2=88$ dan taraf signifikansi $5 \%$, sehingga diperoleh harga $\mathrm{t}^{\text {tabel }} 2,00$, karena $t_{\text {hitung }}>t_{\text {tabel }}(27,24>2,00)$ maka $\mathrm{H}_{0}$ ditolak dan Ha diterima. Hal ini berarti terdapat perbedaan yang signifikan.

Mencermati hasil penelitian yang telah dipaparkan di atas berupa kaji tindak pembelajaran dengan judul Pengaruh modal kooperatif tipe NHT dalam Setting Lesson Study terhadap Hasil Belajar Pendidikan Jasmani Mahasiswa PGSD FIP Undiksha Semster IV khususnya hasil belajar lompat jauh gaya jongkok daalam penelitia ini diyakini akan dapat memberikan kontribusi yang sangat berharga dalam menunjang pembangunan, khususnya pembangunan dan perbaikan kualitas perbaikan pendidikan jasmani di sekolah dasar. Hal ini dikarenakan mahasiswa PGSD sebagai calon guru-guru sekolah dasar yang berkewajiban untuk membelajarkan penjas dengan benar dan menarik agar siswa sekolah dasar merasakan pengalaman yang menyenangkan dalam melakukan dan mengikuti pembelajaran penjas. Pada bagian ini pembelajaran penjas yang menyenangkan dan mudah diikuti oleh siswa diyakii dapat memecahkan masalah ketiadaan model pembelajaran jasmani yang adaptable atau efektif bagi pengembangan biomotorik siswa, misalnya gerak-gerak dasar seperti kekuatan, kelincahan, kordinasi, dsb. Lebih lanjut dijelaskan oleh Ausisie (1996) bergerak bagi anak selain merupakan alat belajar, juga merupakan kebutuhan bagi setiap anak. Untuk itu diperlukan waktu yang cukup dan metode yang tepat untuk bergerak bagi anak terutama bagi anak yang masih sekolah di tingkat sekolah dasar. Pada saat bergerak anak dapat memenuhi kebutuhan geraknya. Kebutuhan akan geraknya ini tidak mungkin dipenuhi pada jam pelajaran di sekolah saja. Oleh karena itu guru pendidikan jasmani harus dapat memenuhi kebutuhan gerak anak didiknya dengan berbagai alternatif gerakan yang dapat dilakukan siswa saat jam istirahat atau di rumah.

Menurut Clarapade begerak bukan hanya memberi pengaruh positif terhadap pertumbuhan organ tubuh anak yang disebabkan karena aktif begerak. Bergerak juga berfungsi sebagai proses sublimasi artinya suatu pelarian dari perasaan tertekan yang berlebihan menuju hal-hal yang positif. Melalui sublimasi anak akan menuju arah yang lebih mulia, lebih indah, lebih kreatif.

Pentingnya olahraga atletik bagi usia anak sekolah dasar bukan tanpa alasan. Hal ini dikarenakan olahraga atletik merupakan wahana yang cukup strategis untuk dapat dilakukan dan dikembangkan baik di sekolah maupun di rumah. Denan melakukan pembelajaran olahraga atletik yang tepat dan bermakna bagi siswa juga gurunya setidaknya turut berkontribusi pada pembentukan manusia-manusia yang sehat jasmani maupun rohani. Melalui olahragaatletik,anak berkesempatan belajar untuk meningkatkan pengetahuan, keterampilan, dan sikap, maupun belajar bekerja sama mematuhi peraturan, menghargai waktu, saling berbagi dan menolong. Olahraga atletik juga dapat melatih konsentrasi atau pemusatan perhatian pada tugas-tugas individu yang harus dilakukan.

Kendalanya adalah terbatasnya lapangan di kota-kota besar, sementara banyak olahraga yang memerlukan arena yang luas. Kendala besar lainnya adalah karena larangan dari orang tua. Mereka takut anak-anak mereka terluka, Hasilnya, banyak orang tua yang memberikan mainan elektronik yang disukai anak.padahal mainan ini cenderung membuat 
anak sulit bersosialisasi sehingga anak menjadi pemalu, penyendiri dan individualistis. Juga makin banyak anak menjadi obesitas karena jarang bergerak.

\section{SIMPULAN}

Hasil belajar penjas pada mahasiswa PGSD FIP Undiksha UPP Denpasar semester IV tahun kuliah 2017. Yang dibelajarkan dengan menggunakan model kooperatif tipe NHT dalam setting lesson study mengalami kemajuan lebih baik daripada yang terjadi pada kelas kontrol. Hasil belajar penjas pada mahasiaswa PGSD Undiksha UPP Denpasar semester IV tahun kuliah 2017 yang dibelajarkan secara konvensional tidak terlalu besar peningkatan hasil belajar. Terdapat perbedaan yang signifikan hasil belajar penjas antara mahasiswa PGSD Undiksha UPP Denpasar semester IV tahun kuliah 2017 yang dibelajarkan dengan model kooperatif dalam setting lesson study dan mahasiswa yang dibelajarkan secara konvensional.yang dibuktikan dengan hasil perhitungan bahwa $t_{\text {hitung }}>t_{\text {tabel }}(27,24>2,00)$. Maka $\mathrm{H}_{0}$ ditolak. Atas hasil tersebut dapat disimpulkan bahwa kedua kelas terteliti dinyatakan memiliki perbedaan yang signifikan. Artinya bahwa model kooperatif tipe NHT berpengaruh positif terhadap hasil belajar pendidikan jasmani PGSD FIP Undiksha UPP Denpasar semester IV tahun ajaran 2016/2017.

\section{DAFTAR PUSTAKA}

Ahmadi, A. (2005). Strategi belajar mengajar. Bandung: Pustaka Setia.

Arikunto, S. (2010). Manajemen penelitian. Jakarta : Rineka Cipta.

Arikunto, S. (2009). Dasar-dasar evaluasi pendidikan. Jakarta: Bumi Aksara

Aziz Syamsir. (2004). Pembelajaran permainan kecil. Jakarta: Depdiknas.

Cholik, T., \& Rusli L. (1997). Pendidikan jasmani dan kesehatan. Jakarta: Ditjen Pendidkan Tinggi. Proyek Pengembangan Pendidkan Guru Sekolah Dasar Depdikbud

Koyan, I. W. (2011). Statistik pendidikan. Singaraja : Undiksha Press.

Muhfida. (2010). Pembelajaran konvensional. Retrived from: http://muhfida.com/pembelajaran konvensional/

Oka Negara, dkk. (2009). Efektivitas penggunaan metode bagian-keseluruhan (Part whole method) dalam meningkatkan keterampilan bermain sepak bola pada siswa kelas $\mathrm{V}$ sekolah dasar. Hasil penelitian tidak dipublikasikan.

Sugiono. (2012). Metode penelitian kuantitatif kualitatif dan $R \& D$. Bandung : Alfabeta.

Sukintaka. (2003). Permainan dan metodik. Jakarta: Dirjen Pendidikan Guru dan Tenaga Teknis Depdikbud.

Syamsyuri \& Ibrahim. Lesson study. Malang. UM Press.

Syarifuddin. (1998). Pendidikan jasmani dan kesehatan. Jakarta: Gramedia Widiasarana

Winarsunu, T. (2009). Statistik dalam penelitian psikologi pendidikan. Malang: UM Press.

Yamin, M. (2011). Paradigma baru pembelajaran. Jakarta: Gunung Persada Press. 